\title{
Black pleural effusion: an unusual complication of pseudocyst pancreas
}

\author{
Spandana Jagannath*, Ashok Kumar
}

Department of General Surgery, Lady Hardinge Medical College, New Delhi, India

Received: 10 May 2021

Accepted: 08 June 2021

\section{*Correspondence:}

Dr. Spandana Jagannath,

E-mail: jagannathspandana@gmail.com

Copyright: (c) the author(s), publisher and licensee Medip Academy. This is an open-access article distributed under the terms of the Creative Commons Attribution Non-Commercial License, which permits unrestricted non-commercial use, distribution, and reproduction in any medium, provided the original work is properly cited.

\begin{abstract}
Pleural effusion following rupture of pancreatic pseudocyst into the pleural cavity resulting into pancreaticopleural fistula is an extremely uncommon complication of acute pancreatitis. Pancreaticopleural fistula also results from disruption of a major pancreatic duct usually due to an underlying pancreatic disease (chronic pancreatitis), trauma, or iatrogenic injury. Pleural effusion is predominantly left sided; however, right-sided and bilateral effusion occurs in $19 \%$ and $14 \%$ of patients respectively. The pleural effusate can be either serous, serosanguinous or black in colour. Analysis of pleural fluid for raised amylase will confirm the diagnosis and investigations like computed tomography (CT), endoscopic retrograde cholangiopancreatography (ECRP) or magnetic resonance cholangiopancreatography (MRCP) may establish the fistulous communication between the pancreas, pseudocyst and pleural cavity. The optimal treatment strategy has traditionally been medical management with thoracocentesis and/or tube thoracostomy and exocrine suppression with octreotide and ERCP stenting of the fistulous pancreatic duct. Surgery, in the current era, is considered in the event patient fails to respond to conservative management or the patient's condition deteriorates. We report the case of a 24-years-old gentleman who was diagnosed with chronic idiopathic pancreatitis with pseudocyst who developed right sided black pleural effusion.
\end{abstract}

Keywords: Black pleural effusion, Pancreaticopleural fistula, Pseudocyst pancreas

\section{INTRODUCTION}

The incidence of pancreatic pseudocyst causing pancreaticopleural fistula is extremely low $(0.4-4 \%) .{ }^{1}$ It is more common on the left side $\left(2 / 3^{\text {rd }}\right.$ cases). The key diagnostic aim in these cases is to determine the nature of the pleural effusion, especially the presence of an elevated amylase concentration (>1000 IU/l). Because of the rarity of this disease, therapeutic strategies are still undefined. A brief report of a 24-year-old gentleman, with pseudocyst pancreas (of unknown etiology), who presented with black pleural effusion is made and treatment strategies discussed.

\section{CASE REPORT}

A 24-year-old gentleman presented with early satiety and upper abdominal fullness for 4 months. He had an epigastric mass of size $15 \times 10 \mathrm{~cm}$ and was diagnosed with chronic pancreatitis, of unknown aetiology, with pseudocyst. CECT abdomen and chest revealed a pseudocyst pancreas of size $20 \times 20 \times 12 \mathrm{~cm}$ with a minimal right pleural effusion of depth $2.5 \mathrm{~mm}$ (Figure 1). A diagnostic pleural tap was done. Biochemical analysis revealed that the effusion was reactionary in nature. As the patient was awaiting surgery, he developed sudden severe breathlessness, pain on the right side of his chest and dry cough. Chest X-ray revealed a massive right pleural effusion (Figure 1C). An intercostal drain was placed on the right side, and $2 \mathrm{~L}$ of black colour fluid was immediately drained. Pleural fluid analysis revealed significantly raised levels of amylase and lipase (26910 IU/1 and >1500 IU/l respectively). A diagnosis of pseudocyst pancreas rupturing into the right pleural cavity was made. Serum and pleural fluid CA 125 and CEA levels were normal and malignant cytology were negative. MRCP revealed a dilated pancreatic duct $(3.7 \mathrm{~mm})$ and right pancreaticopleural fistula (Figure 2). 


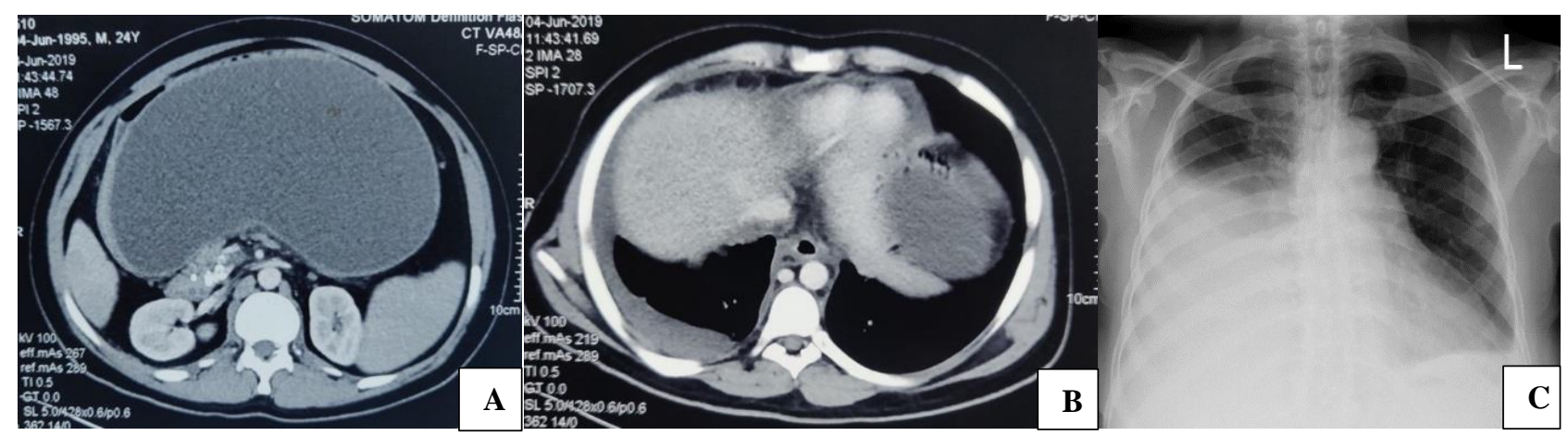

Figure 1: CECT abdomen and chest cross sectional images showing (A) pseudocyst pancreas of size $20 \times 20 \times 12 \mathrm{~cm}$; (B) right pleural effusion of depth $2.5 \mathrm{~mm}$; (C) chest X-ray showing right sided massive pleural effusion.

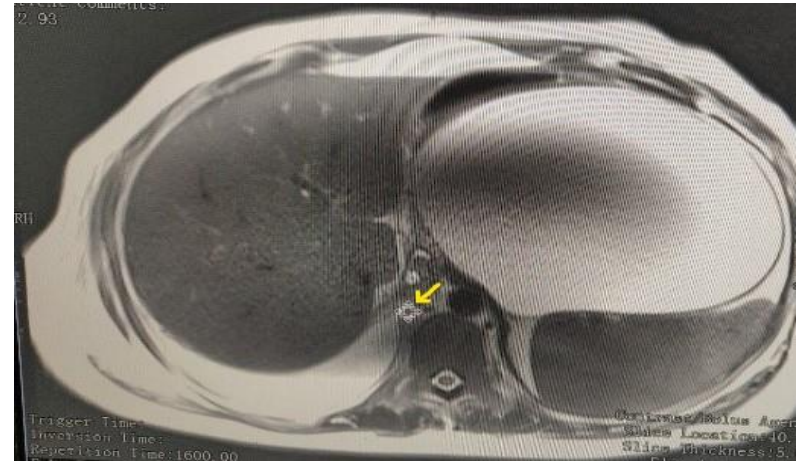

Figure 2: MRI Abdomen with MRCP showing a hyperintense tract extending from one of the locule of right pleural collection through the diaphragm just adjacent to IVC, traversing through the left of caudate lobe and reaching up to pancreatic head s/o pancreaticopleural fistula (arrow).

In view of non-response to the initial conservative management of intercostal drainage with somatostatin analogue, and rapid worsening of his general condition, he was taken up for surgery. An open cystogastrostomy was done and around 5L of black colour fluid was drained. Post op recovery was rapid and subsequently chest tube was removed. On follow up, CECT abdomen and chest revealed a healed fistula.

\section{DISCUSSION}

Pancreaticopleural fistula following rupture of pancreatic pseudocyst causing pleural effusion was first described in the $1960 \mathrm{~s}^{2}$ The fluid enters the pleural cavity via the path of least resistance, normally via the oesophageal hiatus or more rarely through the transdiaphragmatic route, and empties into one ( $76 \%$ on the left, $19 \%$ on the right) or both pleural spaces (14\%). ${ }^{3,4}$ Males constitute four-fifths of the cases. Dyspnoea (in 65-76\% of cases), abdominal pain $(29 \%)$ cough $(27 \%)$, chest pain $(23 \%)$, and fever are the usual symptoms. ${ }^{5}$ Pleural effusion can be serous, serosanguinous or black. Unlike the other forms of pleural effusions, which are normal and well-studied, black pleural effusion (BPE) is uncommon and has been studied to a lesser extent. ${ }^{6}$ It is primarily due to deposition of hemosiderin caused by breakdown of the haemoglobin by the pancreatic enzymes.

Diagnosis is difficult and necessitates a high index of suspicion. Pleural fluid amylase levels are typically above $1000 \mathrm{U} / \mathrm{L} .{ }^{5,7}$ The sensitivity of visualising the fistulous tract by CT is $47 \%$, ERCP is $78 \%$ and MRCP is $80 \% .^{5}$

Treatment options include pancreatic rest including NJ feeding, chest drainage, somatostatin analogue, pancreatic enzyme replacement and endoscopic drainage and/or stent placement and surgical drainage. Surgical intervention is the definitive line of management for pancreaticopleural fistula following rupture of pseudocyst pancreas. However, surgery is resorted to only after failure of medical or endoscopic treatment or if the patient's condition deteriorates. Surgical procedures performed are cystogastrostomy, cystojejunostomy and/or pancreatic resections, depending on the proximity of the pseudocyst to the draining organs and pancreatic portion involved.

We preferred surgical drainage in our patient because- (a) MRCP did not reveal any communication between the pancreatic duct and the cyst or between the duct and the pleural cavity; (b) the role of endoscopic drainage of a large cyst is still under evaluation. Moreover, it takes a longer time and repeated sittings $(>4)$; and (c) further delay in the treatment for the pancreaticopleural fistula causes more damage to the already compromised lung.

\section{CONCLUSION}

In patients with pseudocyst of pancreas presenting with sudden severe dyspnoea and massive pleural effusion, a pancreaticopleural fistula following rupture of pseudocyst should be suspected. An increased level of pleural fluid amylase (in thousands) is diagnostic of the pancreaticopleural fistula. Immediate ICD placement followed by surgery should be performed as soon as possible to prevent further enzymatic damage to the lungs.

Funding: No funding sources

Conflict of interest: None declared

Ethical approval: Not required 


\section{REFERENCES}

1. Burgess NA, Moore HE, Williams JO, Lewis MH. A review of pancreatico-pleural fistula in pancreatitis and its management. HPB Surg. 1992;5(2):79-86.

2. Uchiyama T, Suzuki T, Adachi A, Hiraki S, Iizuka N. Pancreatic Pleural Effusion: Case Report and Review of 113 Cases in Japan. Am J Gastroenterol. 1992;87(3):387-91.

3. Cazzo E, Apodaca RM, Gestic MA, Chaim F, Saito $\mathrm{H}$, Utrini MP, et al. Management of pancreaticopleural fistulas secondary to chronic pancreatitis. Arq Bras Cir Dig. 2017;30(3):225-8.

4. Sut M, Gray R, Ramachandran M, Diamond T. Pancreaticopleural fistula: a rare complication of ERCP-induced pancreatitis. Ulster Med J. 2009;78(3):185-6.
5. Ali T, Srinivasan N, Le V, Chimpiri AR, Tierney WM. Pancreaticopleural fistula. Pancreas. 2009;38(1):26-31.

6. Villena V, Encuentra A, Garcia LR, Echave SJ, Martínez CJ. Clinical implications of appearance of pleural fluid at thoracentesis. Chest. 2004;125(1):156-9.

7. Rockey DC, Cello JP. Pancreaticopleural fistula. Report of 7 patients and review of the literature. Medicine. 1990;69:332-44.

Cite this article as: Jagannath S, Kumar A. Black pleural effusion: an unusual complication of pseudocyst pancreas. Int Surg J 2021;8:2238-40. 